\title{
Site Selection for Restoration Planning: A Protocol With Landscape and Legislation Based Alternatives
}

\author{
Verônica F. Gama ${ }^{1}$, Alexandre C. Martensen²,3, Flávio J. Ponzoni ${ }^{4}$, \\ Márcia M. Hirota ${ }^{5}$ \& Milton C. Ribeiro ${ }^{6}$
}

\author{
${ }^{1}$ The Ecology Centre, The University of Queensland - UQ, St Lucia, Queensland, Australia \\ ${ }^{2}$ Taki Ambiental, Ribeirão Grande, SP, Brasil \\ ${ }^{3}$ Department of Ecology \& Evolutionary Biology, University of Toronto - U of T, Toronto, ON, Canada \\ ${ }^{4}$ Remote Sensing Division, National Institute for Space Research - INPE, São José dos Campos, SP, Brazil \\ ${ }^{5}$ Fundação SOS Mata Atlântica, São Paulo, SP, Brazil \\ ${ }^{6}$ Spatial Ecology and Conservation Lab - LEEC, Department of Ecology, São Paulo State University - UNESP, \\ Rio Claro, SP, Brazil
}

\begin{abstract}
Selecting sites for ecological restoration is an imperative, although challenging task. We developed a spatially explicit model to support site design and prioritization towards ecological restoration. We considered seven distinct and flexible templates, two based on legislation requirements and five on landscape spatial parameters, such as corridor design, enhancements in patch size and shape, and proximity to larger sources areas, thus, with different resilience capacities. We tested the approach on two different scales of analysis: applying the legislation based templates in the Atlantic Plateau of São Paulo, which is part of the Atlantic Forest biome, and the landscape based templates in one of its sub-watersheds ( 150,000 ha), and then calculated landscape indexes to compare the current forest configuration to the resulted simulated restored ones. We showed that our protocol is flexible, transparent and repeatable, thus, could help in decision making towards conservation management.
\end{abstract}

Key words: Restoration Planning, Connectivity, Fragment Size, Site Selection, Spatially Explicit Simulations.

\section{Introduction}

Habitat loss, fragmentation and degradation are driving species to extinction (Butchart et al. 2010) and compromising the maintenance of ecosystems functions and services worldwide (Garcia \& Martinez 2012; Lovett et al. 2005). Various management strategies have been suggested to overcome these major threats, and ecological restoration is one of the most relevant, although expensive, and with variable results (Lamb et al. 2005; Benayas et al. 2009). Most of the degraded landscapes are mosaics of different land uses and patches of native habitats. The effectiveness of restoring key ecological functions in these heterogeneous environments depends on the capacity of restored habitats to complement existing ones (Lamb et al. 2005). Thus, the question practitioners frequently face is: which part and proportion of the landscape should be reforested, especially when the budget is limited?

\footnotetext{
*Send correspondence to: Verônica Fernandes Gama The Ecology Centre, The University of Queensland - UQ, St Lucia, Queensland 4072, Australia E-mail: veronica.gama@uq.net.au
}

In modified landscapes, the spatial arrangement of restoration initiatives influences species conservation status (Bell et al. 1997; Gilbert-Norton et al. 2009). Spatial features such as fragment size, connectivity, edge effects and their relative locations to one another are all important drivers of species richness, abundance and composition (Saunders et al. 1991; Andrén 1994; Martensen et al. 2012). Fragment size is directly related to population size, and consequently to population viability. Connectivity is a key factor in the maintenance of individuals in fragmented habitats (Martensen et al. 2008), as well as in (re)colonization dynamics (Gilbert-Norton et al. 2009), and is consequently relevant for metapopulation persistence. Edge effects are known to reduce the amounts of available habitat within a given patch for sensitive species (Bergès et al. 2013), although fragment edges promote important exchanges of individuals, seeds, propagules and nutrients, which ultimately influence resilience/regeneration around patches (Holl \& Aide 2011).

Researchers have recently started to incorporate the landscape spatial arrangement when trying to allocate and design sites 
for ecological restoration (Twedt et al. 2006; Thomson et al. 2009; Tambosi \& Metzger 2013; Echeverria et al. 2013, Tambosi et al. in press). Usually the main proposed strategies are: i. increasing patch size, taking advantage of higher resilience adjacent to remaining habitats (Holl \& Aide 2011); ii. incrementing patch connectivity (Metzger et al. 2008; Tambosi et al. in press); or iii. prioritizing restoration in compliance with environmental legislation (Metzger 2003, 2010; Rodrigues et al. 2009, 2011).

However, there are few spatially explicit tools to pinpoint the precise locations for restoration projects, so scientific knowledge is often not applied in "on the ground" restoration projects. To our knowledge none of these available tools can assist restoration planning at multiple scales (but see Tambosi \& Metzger 2013) with a variety of restoration options such as corridors and/or enlarging existing patches and/or using riparian areas. For example: The Corridor Designer (Majka et al. 2007) selects sites for designing corridors only. Moreover, some tools are available for site selection towards conservation, such as GUIDOS, which highlights existing corridors or corridor zones (Joint Research Center - European Commission 2011). However none of them allow the users to explore different restoration strategies, which is a common task in restoration projects. To fill this gap, we proposed a multi-option protocol that integrates a set of simple rules, as well as geoprocessing techniques, in order to assist restoration planning to (1) design restoration sites, and to (2) prioritize them in terms of importance according to spatial structure relevance.

To explore the possibilities of the proposed protocol we conducted a case study in the Atlantic Plateau of São Paulo. It is an interesting region to test this protocol, since it holds the largest remaining tract of Atlantic Forest, as well as a myriad of smaller patches. Many of these smaller fragments surround that large one, acting as both buffer zones to mitigate the surrounding impacts on the larger protected area as well as receiving the benefits of being closely located to this large forest tract (Martensen 2008). This means that restoring native habitats in the region could increase the potential of the local Nature Reserves to act as source-areas and consequently maintain biodiversity in the more degraded surrounding landscapes. We investigated the state of conservation of the region regarding the former Brazilian Forest Act with maps of the year 2005 and then selected one of its sub-watersheds to simulate and compare different restoration strategies.

\section{The Proposed Protocol}

The first step in any prioritization exercise is to define clear objectives regarding the expected outcomes, based on an available budget. Our proposed protocol is fully spatially explicit, entirely based in Geographical Information System (GIS), thus the visualization of the different strategies helps to identify the adequacy to the objectives. We suggest seven basic criteria for site designing to be used separately or sequentially in order to: i) comply with the former Brazilian environmental legislation (Forest Act - 4.771 15/1965), and ii) enhance landscape structure features, such as improving connectivity by restoring corridors and/ or increasing fragment areas.

\section{Scenario description and calculations}

The main input data is a vector map composed of two classes, habitat and non-habitat. Thus, we assume that everything that is not habitat is restorable, which is clearly a simplification of real landscapes, since urban areas or roads, are usually not possible to be restored. Secondly, we add as attributes for each fragment a unique patch ID and its respective area.

\section{Legislation-based criteria}

While our protocol is flexible enough to represent different legislation alternatives, we opted to apply the former Brazilian Forest Act (4.771 15/1965) for two main reasons: i) to analyze the compliance with the former legislation; and ii) because the current legislation defines the amount of native habitat that should be preserved based on different characteristics of the private properties, for example their sizes, and this information is still largely unavailable, at least before the universality of the Rural Environmental Cadaster (Cadastro Ambiental Rural - CAR).

The Brazilian Forest Act defines two groups of areas that should be preserved: the (a) Permanent Protected Areas - PPAs and (b) Legal Reserves - LRs. The PPAs include riparian areas along rivers, water springs, steep terrains $\left(>45^{\circ}\right)$, and high elevations (> $1800 \mathrm{~m}$, details Table S1). The LRs denote areas designated for conservation or forest management that should cover a percentage each private property, excluding the PPAs. This percentage varies among the Brazilian biomes, and in the Atlantic Forest is 20\%, except for family owned properties whose amount could be calculated considering the PPAs, or other types of low intensive land-uses, such as orchard (CONAMA 2010). Although our protocol is based in the former environmental legislation, it is flexible enough to be adequate to the current one, as far as the CAR information becomes available.

In order to generate the PPAs template we used five input maps: drainage, hydrography and dams for the PPAs of rivers, lakes and reservoirs, and elevation and slope for the PPAs above $1800 \mathrm{~m}$ of altitude and of steep terrains (slope $>45^{\circ}$ ). Then, the PPAs map is superimposed with the original forest cover map, and the non-overlapping polygons are set as "degraded PPAs", which alone can be used to guide actions. Moreover, to define the Legal Reserves (LRs), two other maps are required, the Strictly Protected Nature Reserves (NRs) and the map of the extent for which we want to select areas to dispose the LRs. Maps of private properties boundaries are usually unavailable (see above) so as supported by the law. So we suggest calculating the 
proportion of land to be preserved as LRs out of a larger region (e.g. the watershed), and latter pinpointing restoration spots based on the landscape-based criteria described below. Additionally, the current legislation defines that the LRs could be set in any place within the biome. Although this procedure could be conducted in a much broader scale, we recommend a different type of analyzes for such a broad scale (e.g. Tambosi et al. in press). Since all areas except PPAs and NRs are possible candidates for LRs, the PPAs map is also needed.

\section{Landscape-based criteria}

Landscape-based criteria encompass five potential templates, which can be used alone or combined in a chosen sequence until the defined target is achieved (e.g. species is wellpreserved, or fragments are structurally connected) and/ or the restoration constraint (budget or time) is reached. They can be divided in three categories: i) predominantly improving connectivity; ii) predominantly improving fragment size; and iii) enhancing connectivity and fragment size/core area. These options are: (a) to create corridors with fixed width, (b) enhanced connections, (c) corridors using Permanent Preservation Areas, (d) resilience zones and (e) enlarge forest patches.

The different biological attributes used to characterize the landscape based templates, for example, corridor use according to its width, or species dispersal capacities should be based on available biological data. For example, the functional connectivity, which encompasses species' biological response to landscape structures (Wiens 1997), could be different of the exclusively structural one. For instance, for a given species that is able to cross certain distance between patches, fragments that are located within this distance, although not structurally connected, are functionally connected for this particular species (Martensen et al. 2008). In cases where biological data is not available, a range of values could be used and sensitivity analyses should be performed to investigate variability in the results.

One of the values to be defined by the users is the search distance to structurally link fragments. To create the template of corridors with fixed width, the user should first define the maximum Euclidian distance to be searched from the fragments. Each fragment will then be linked by corridors to its neighbor fragments which are within this chosen distance. This maximum search distance will be the maximum length of the corridors. The width of the corridors should also be user defined, and both values for length and width should preferentially be chosen with biological information as support. To process those corridors, buffers of half the size of the selected Euclidian distance should be generated, without dissolving the polygons. Then, a new map should be generated, only with the intersections between these buffers. Latter, the centroid of these intersections should be converted to points, which will be halfway between each pair of fragments separated by no more than the maximum selected Euclidian distance. Each point should receive a unique ID and a buffer slightly larger than the previous one should be done around those points. This will ensure that all generated circles intersect at least two forest patches. Again isolate the intersections of these buffers with the fragments and generate points from each of their centroids intersections. Each pair (or group) of points generated from the same buffer will be assign the same ID. Then, create lines linking the points with the same ID. These lines are the corridors, which will be widened with a buffer half the size of the defined corridor width. Last, the overlaps of the corridors with the patches must be erased, and the desired attributes can be added to each corridor. We suggest: Corridor ID, area, IDs of the two patches it connects, sum of the areas of these two patches, ID of the group of connected fragments and the corridor itself, and area of this newly structurally linked cluster of fragments. When more than one corridor is generated between same patches, the larger one should be erased.

From another side, structurally linked fragments, could not be functionally linked in cases where the target species does not use corridors or any area with short width. This can also be conceived for fragments that are short distance apart from each other, and thus, are functionally connected for some species, while isolated for others. In these cases, the user might want to Enhance the connections between these fragments by only selecting the ones for which wide connections are possible. These corridors result from two main steps: (1) Considering a cluster of fragments at a certain maximum search distance, make a buffer around these fragments, and dissolve the buffer by the ID of this cluster; (2) followed by a negative buffer. A few tests may be carried out by the user, since different buffer sizes will result in different areas for restoration. After a number of tests, we observed that buffering the vegetation map with any size larger than $2 / 3$ of the desired enhancement of connectivity desired, generate the best results. Narrower buffers will vanish during the negative buffer step and wider ones will generate many redundancies of connections. Another observation we made is that the negative buffer must be at least one meter wider than the original buffer to minimize the appearance of artifacts around the fragments, such as polygons that are not corridors, i.e. do not link two different fragments. The final step is to erase the new layer with the vegetation map, which will result in a layer exclusively with corridors and some remaining artifacts (polygons that do not link different fragments). The latter ones are easily erased by excluding all polygons that are exclusively linked to only one fragment, i.e., not linking two or more fragments, thus, not acting as corridors. The attributes that we created for these corridors were: unique ID, area, number of patches it connects, IDs of the patches it connects, ID of the cluster of fragments it is part, and the area of the cluster of fragments. 
Although a commonly proposed technique, corridors are not simple to apply in the field, since they require a particular area to be restored, i.e. between two or more fragments which landowner might not be willing to change its land use. When this happens, restoring the PPAs would be an option, since these areas could be used as corridors or at least shorten the distance between existing fragments. To identify the PPAs that actually link at least two fragments, first the user needs to merge the original vegetation map with the PPAs map, and latter convert the resulted map in a raster grid. We recommend the use of GUIDOS 1.3 software (Joint Research Center - European Commission 2011) to identify the corridors which connect two or more habitat patches. Finally, landscape structure parameters could be used to evaluate the importance of restoring each PPA, and thus, a prioritization could be conducted.

Since restoration procedures are expensive, and with variable results, some authors have argued that the focus should be on sites that could be recovered mainly by autogenic processes. In these areas, less intervention is necessary to promote natural vegetation recover, which constitutes an interesting alternative. Cost is lower when compared to fully active restoration, as well as the chances of achieving the restoration objectives is higher (Lamb et al. 2005; Holl \& Aide 2011). Here we defined Resilience zones as areas which are benefited by resources, such as seeds, propagules, nutrients, or any other biotic or abiotic factor provided by adjacent source-areas. Again, source-areas should be defined based on the best available data, and are usually defined as the largest remnants of the analyzed region, or patches that present a given target species. The procedure after selecting the source-areas is to make a buffer of a small size (usually $<100 \mathrm{~m}$ ) around these areas, and latter to prioritize them according to the landscape structure attributes of each of them, such as its capacity to link two or more fragments.

Given the higher resilience around fragments, users can select the template Enlarge forest patches, which is a criterion that increases fragment size by "filling" invaginations in its shape, thus turning patches into a more circular shape, reducing edge effects and enhancing core area, as well as making use of these highly resilient regions. The procedure to generate this template starts with buffering the vegetation map, then, applying a negative buffer at least a meter larger than the previous one (to avoid creating artifacts around the fragments). Latter, erase the original vegetation and use the transformation Multipart to Singlepart Features. This processing might need some testing by the user since a larger buffer will created larger increments and a smaller buffer smaller increments, not "filling the invaginations". Finally append to each feature its ID and area.

\section{Prioritizing and selecting sites}

After designing the scenario(s), the next step is to spatially evaluate each of them and append any other desired attributes to the features, such as: area and unique ID of the sites, forest patches they are adjacent to and functional clusters (i.e. clusters of functionally connected patches based on the pre-defined search distance), proximity to sites of interest (for example, Nature Reserves, or a site of occurrence of a target species), cost of restoration, among many other - see supplementary material ${ }^{* *}$, and FRAGSTATS documentation (McGarigal et al. 2012) for some metrics details.

After having the map with the candidate sites for restoration and with all attributes for each polygon, the user is ready to prioritize the areas. This step is done by table manipulation, where attribute values are reordered according to the user's priorities for restoration, such as from the largest to smallest size or from farthest to closest. Finally, on this reordered table, the user will be able to select the desired sites among all possibilities, and to visually evaluate by comparing different maps. Multiple attributes may be prioritized and selected at the same time with statistical functions available in several GIS. The output map shows polygons, which represent the candidate sites to be restored, each one with the necessary attributes for the sites prioritization (such as ranking by area or location) and selection (choosing only the desired ones in the rank).

A step-by-step flowchart for the proposed protocol is shown in Figure 1, and a schematic representation of potential outputs for each restoration option in Figure 2.

\section{The Case Study}

For the entire Atlantic Plateau of São Paulo and for each of its SWSs (Figure 3), we obtained the preserved and non-preserved PPAs, the amount of LRs required, and the amount of forest remnants that could be set as LRs. Later, for one of these SWSs (São José de Guapiara SWS), we applied each one of the five Landscape-based criteria and evaluated its spatial characteristics (Table 1) for the current forest cover map and for each different simulated scenario, in order to compare the changes promoted. We used the software Patch Analyst 5.1 (Rempel et al. 2012) to calculate the landscape metrics accessed in the comparison - see supplementary material for metrics details.

Nearly 2.5 million ha of The Atlantic Plateau is still preserved $(40.35 \%)$. Around 716,720 ha of forests ( $29.1 \%$ of the remaining forest) are located in Nature Reserves, where $8.56 \%$ of the area lacks forest vegetation. About 133,391 ha of the total forest are located in PPAs, representing 5.45\% of the remaining forest, and PPAs cover around $8.3 \%$ of the region. However, almost $3 / 4$ are degraded (73.6\%). Forest patches that could be considered as LRs account for $1,611,642$ ha, or $65.43 \%$ of the total forest vegetation, which represents $26.4 \%$ of the entire region (Table S2). The native vegetation cover varies greatly between SWSs, from more than $70 \%$ in 27 of them, to less than $30 \%$ in 26 SWSs (Table S3).

${ }^{* *}$ see supplementary material available at abeco.org.br. 


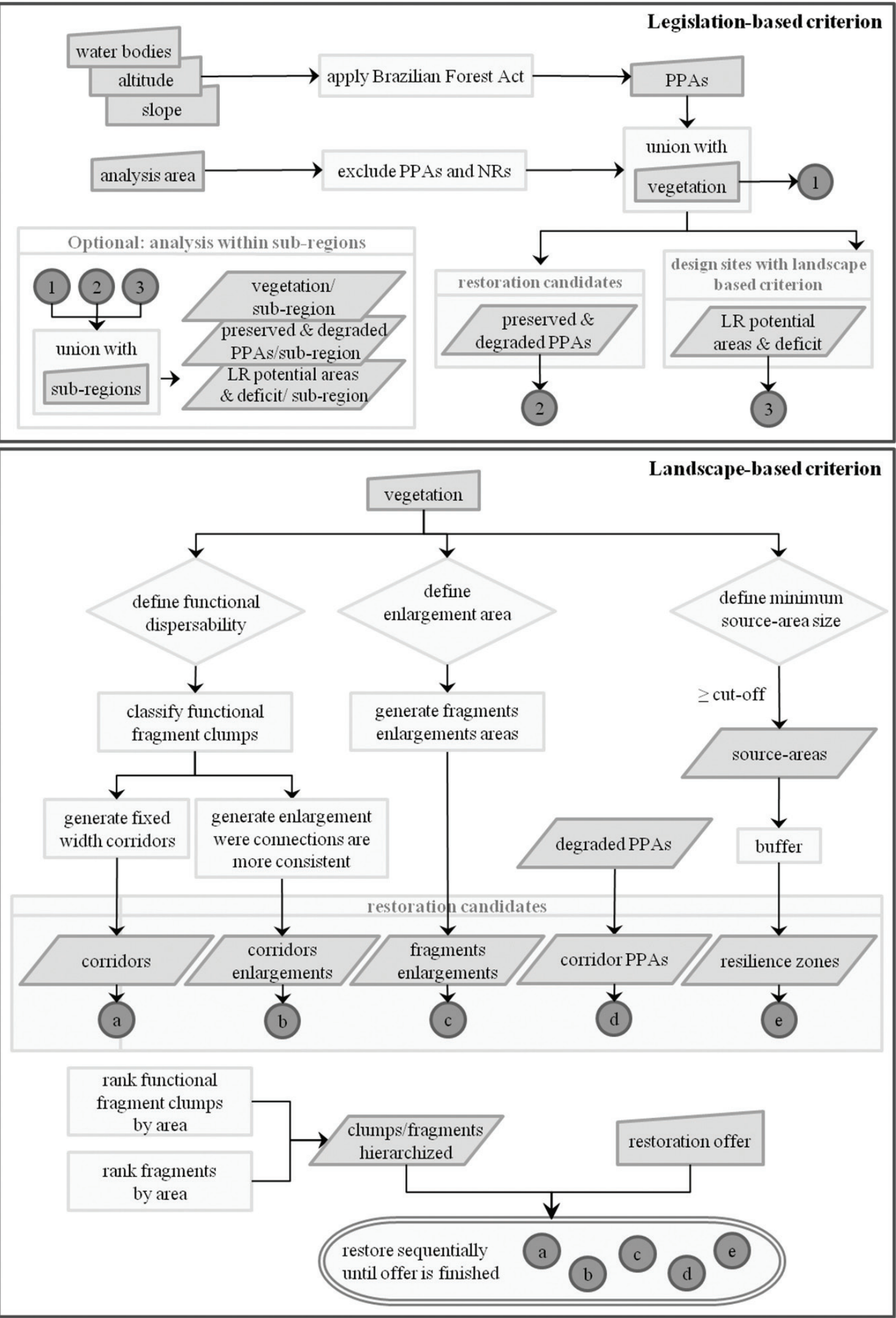

Figure 1. Flowchart of the methods used to process input data, generate restoration candidates, select and prioritize sites for restoration. Abbreviations: PPA = Permanent Protected Areas; LR=Legal Reserves; SWS=Subwatersheds; NR=Nature Reserves. 

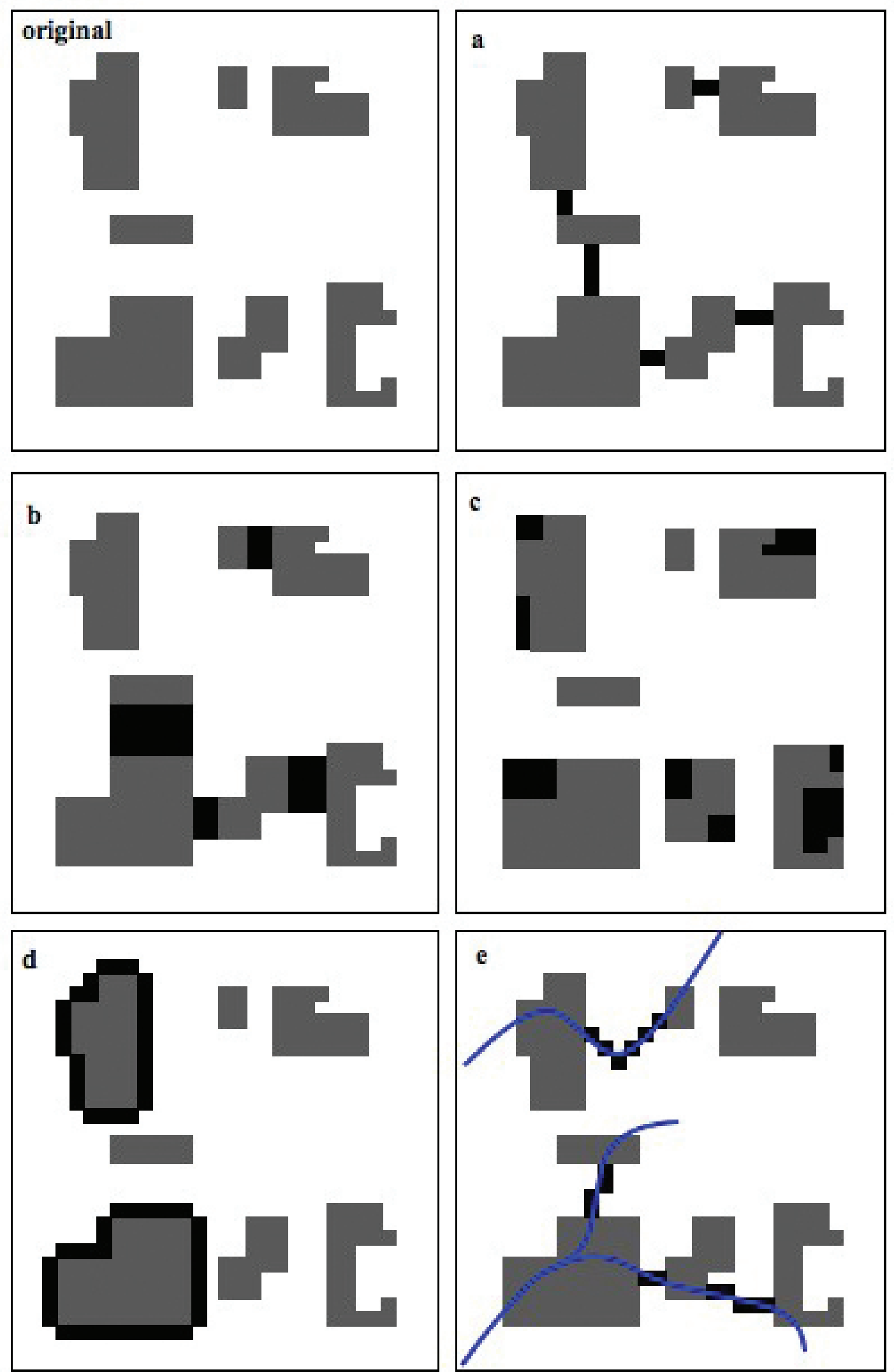

Figure 2. Schematic representation of restoration options proposed in this research: original landscape, a=fixed width corridors, $\mathrm{b}=$ enhanced connections, $\mathrm{c}=$ enlargement of patches, $\mathrm{d}=$ resilience zones and $\mathrm{e}=$ corridors of Permanent Protected Areas. Grey areas denote the original forest remnants, black are restoration candidates, and blue lines in "e" are drainages. 


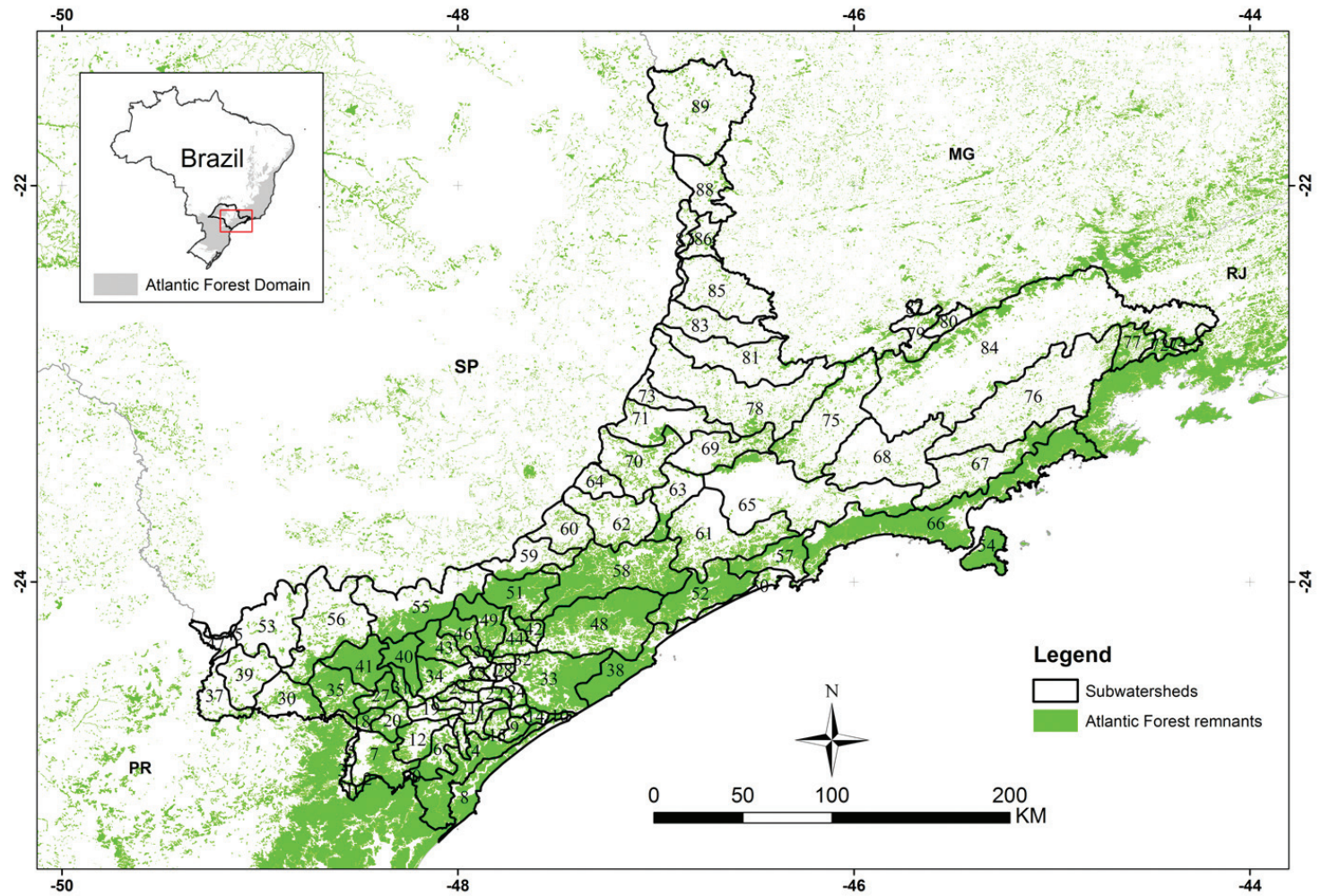

Figure 3. Location of the ninety subwatersheds in the Atlantic Plateau of São Paulo Region. Guapiara Basin is the 56th subwatershed in the western region of the study area.

São José de Guapiara SWS has 46,428 ha of remaining forests (30.96\% of its area), with 3,763 ha $(8.1 \%)$ in PPAs, 1,984 ha $(4.3 \%)$ in Nature Reserves and 40,637 ha (87.56\%) apt to be LRs (Table S4). The total forest area that could be accounted as LRs represents $27.1 \%$ of this SWS. The total vegetation is distributed among 1007 patches (Table 1 and Figure $\mathbf{S 1}$ ).

Without considering edge width (to enable direct comparison between the two corridors criteria), fixed width corridors and enhanced connections (Figure $\mathbf{4 a}$ and $\mathbf{b}$ ) both reduced the number of patches to 719 (Table 1 and Figure S1) by structurally linking fragments, thus increasing connectivity. These similar results were expected, since we chose the same search distance to run both cases $(100 \mathrm{~m})$, and did not consider edge avoidance, what would be the main difference between these two templates. In the fixed width corridors scenario we connected every patch that was less than $100 \mathrm{~m}$ apart from another by restoring corridors with $30 \mathrm{~m}$ of width, summing only 66 ha restored. Enhanced connections demanded 1,523 ha of restored area; however, this option increases interior areas in the corridors, thus creating a landscape with more core area, which increased by approximately 6.5 and $7.5 \%$ when considering 50 and $100 \mathrm{~m}$ of edge width respectively (Table 1, Figure S2). Restoring all PPAs corridors (Figure 4e) in the São José de Guapiara $S W S$ would add 3,427 ha of vegetation area, with a major impact in connectivity, reducing the number of fragments of the landscape from 1007 to only 170 .

In the Enlarge forest patches scenario we added 7,766 ha of restored areas, increasing core areas by approximately $37 \%$ and $54 \%$ for 50 and $100 \mathrm{~m}$ of edge width, respectively. For the Resilience Zones scenario we added 2,864 ha of restored area in the landscape, increasing core areas by approximately $10 \%$ and $33 \%$ for 50 and 100 m edge, respectively (Table 1).

\section{Discussion}

Among the main characteristics of our protocol, three are particularly relevant: (i) it is fully spatially explicit, (ii) enables multi-scale approach and (iii) offers a variety of restoration options to be accessed alone or combined. The user can test different scenarios to achieve the restoration goals or manage whole landscapes and obtain a better spatial arrangement of the remaining habitat (Hobbs \& Norton 1996; Bell et al. 1997; Holl \& Aide 2011). Although particularly relevant for decision-making, few tools are available to create different scenarios and compare strategies, which usually leave stakeholders without alternatives, especially when the amount of degraded land far outstrips available resources for restoration. MARXAN (Ball et al. 2009) and C-Plan (Pressey et al. 2009) are among the most important tools used in conservation planning; however there are few examples of their application to restoration planning 


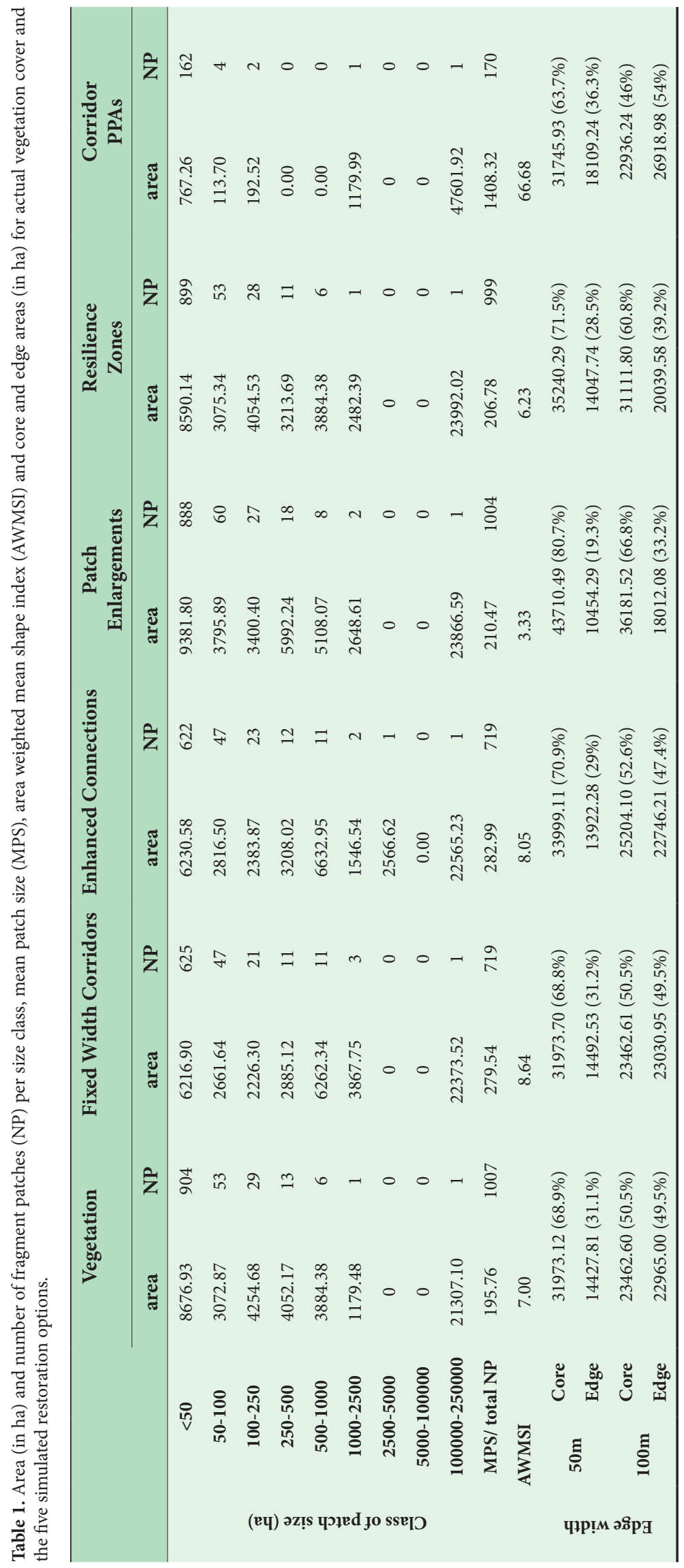



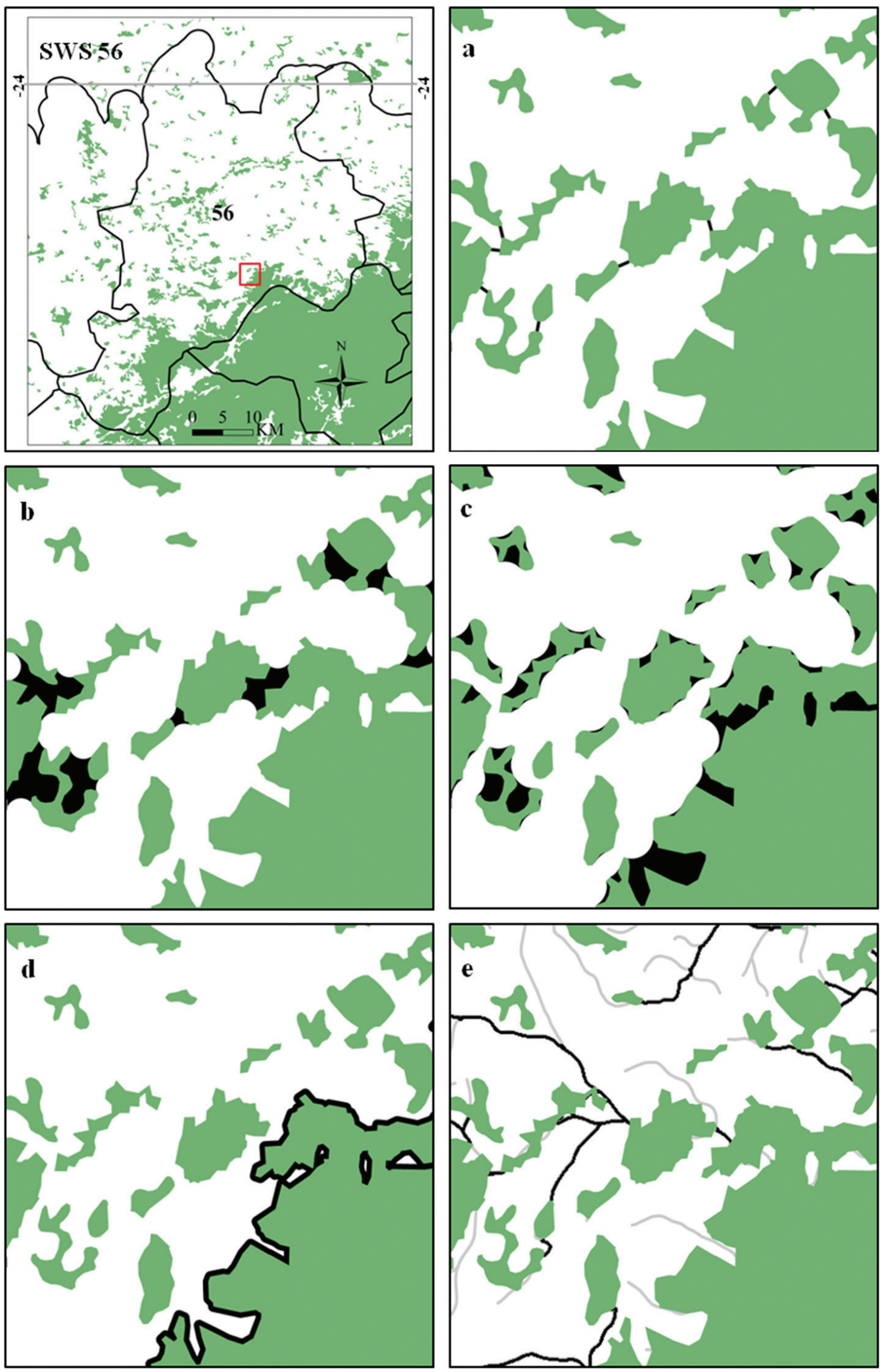

Figure 4. Guapiara subwatershed and a zoomed in view of the detail (red square) showing the results for: a) fixed width corridors, b) enhanced connections, c) enlargements, d) resilience zones and e) corridor of Permanent Protected Areas. Atlantic Forest remnants in green and corridor candidates in black. 
(Mansourian et al. 2005). The proposed protocol offers a set of methods and tools to assist restoration planning, as well as making it possible for all parties involved (e.g. landowners, stakeholders, conservationists, etc.) to better understand and be part of the selection procedure.

Some of the most important management strategies for ecological restoration are: improving connectivity, reducing the proportion of native habitat vulnerable to edge effects, and increasing patch size. Site selection for restoring connectivity via corridors has been shown to be particularly helpful towards biodiversity management (Holvorcem et al. 2011). Our protocol helps the user to design three options for corridors, which can be used independently or combined in sequence to select sites for corridor establishment. With the fixed width corridors template it is possible to connect patches via the shortest distance between them, which is the least costly way (smaller amount of area to be restored) to structurally connect patches. Furthermore, when processing the enhanced connections, it is also possible to locate a cost effective way to increase connectivity, but the sites designated are larger than regular corridors and thus also enhancing the total and core areas of the patches they connect, benefiting edge sensitive species as well. The menu of corridor options also includes the generation of corridors through non-preserved PPAs, which may constitute ecological corridors while benefiting conservation in other ways, such as sediment retention and river protection. Moreover, landowners are more aware of the protection of these tracks of forest, thus, restoration initiatives could be more feasible.

Increased patch size is one of the main focuses of management strategies, since patch size is a key property to species maintenance in fragmented landscapes (Saunders et al. 1991; Martensen et al. 2012). This approach might also include focusing on interior or sensitive species that may avoid forest edges. In this regard, enhanced connections and resilience zones are strategies to be considered. Furthermore, the enlargement fragments template, which prioritizes filling invaginations of irregularly shaped fragments, can be particularly useful for reducing edge effects and consequently benefits sensitive species (Bergès et al. 2013).

Performing the steps of these methods requires prior information. The quality of the input maps and biological information, such as dispersal capacities or size and characteristics of source-areas, can significantly affect where restoration sites are designed. Moreover, biological data is usually not available, thus, the parametrization of biological attributes, which directly affects the scenario definitions, often relies on expert opinions, that are usually not congruent (Cipollini et al. 2005). Nevertheless, it is one of the most important phases of restoration projects, since it makes possible to re-think, re-discuss and re-negotiate previously defined goals. This allows for increased numbers of stakeholders involved in the project, and explores different possibilities for future scenarios considering the opinions of every person involved in the process. The proposed protocol assists in this task, since it makes possible for users to investigate different possibilities through the design, visualization, prioritization and selection of different strategies for restoration.

The recent changes in the Brazilian Environmental Legislation include (1) variation in the percentage of LRs required according to the size of the property considered, (2) reduction in PPA width and (3) consideration of PPAs as LRs (see table in Garcia et al. 2013). If these changes remain in effect, the whole country might experience a decrease in restoration actions in years to come. Firstly, because remote sensing and geoprocessing, which have been key in research and law enforcement, will be less applicable in a context with lack of information on property size. Secondly, the reduction in PPAs width diminishes their capacity to act as corridors (Metzger 2010), as well as to protect water bodies, and to be restored in an economically viable way. Finally, including PPAs in the amount to be preserved as LRs will reduce the amount of land required to be restored. PPAs account for approximately $15 \%$ of the Atlantic Forest biome (Calmon et al. 2011; Ribeiro et al. 2011), whereas LRs used to be considered an additional $20 \%$ of each private property to be preserved. Compliance with the former legislation whether than the current would have placed the Atlantic Forest in a much better conservation status.

Additional protocol developments consider the implementation of the proposed approaches in a software package in ARCGIS, which we will call "Restoration Hotspots Toolbox". The proposed protocol is a tool for decision making that constitutes a major step towards systematic planning for ecological restoration. After clear objectives are stated the protocol can fully support the designing and prioritization of sites for restoration, and even small budgets could be optimized.

\section{Acknowledgments}

We are grateful to both editors of this special issue, Jean Paul Metzger and Pedro Brancalion, for encouraging us to submit this paper for publication. We would also like to thank Pedro Brancalion for selecting excellent referees and also for carefully reviewing this paper himself, which helped us improve it considerably. This study was funded by The National Council for Scientific and Technological Development (CNPq), an agency linked to the Brazilian Ministry of Science and Technology (MCT).

\section{References}

Andrén H, 1994. Effects of habitat fragmentation on birds and mammals in landscapes with different proportion of suitable habitat: A review. Oikos, 71:355-366. http://dx.doi. org/10.2307/3545823

Ball IR, Possingham HP \& Watts M, 2009. Marxan and relatives: Software for spatial conservation prioritisation. In: Moilanen A, Wilson KA \& Possingham HP (eds.). Spatial conservation 
prioritisation: Quantitative methods and computational tools. Oxford: Oxford University Press. v. 14, p. 185-195.

Bell SS, Fonseca MS \& Motten LB, 1997. Linking restoration and landscape ecology. Restoration Ecology, 5:318-323. http:// dx.doi.org/10.1046/j.1526-100X.1997.00545.x

Benayas JMR et al., 2009. Enhancement of biodiversity and ecosystem services by ecological restoration: a metaanalysis. Science, 325:1121-1124. http://dx.doi.org/10.1126/ science. 1172460

Bergès L et al., 2013. Unexpected long-range edge-to-forest interior environmental gradients. Landscape Ecology, 28:439-453. http://dx.doi.org/10.1007/s10980-012-9841-1

Butchart SHM et al., 2010. Global Biodiversity: Indicators of Recent Declines. Science, 328:1164. http://dx.doi.org/10.1126/ science.1187512

Calmon $\mathrm{M}$ et al., 2011. Emerging Threats and Opportunities for Large-Scale Ecological Restoration in the Atlantic Forest of Brazil. Restoration Ecology, 19:154-158. http://dx.doi. org/10.1111/j.1526-100X.2011.00772.x

Cipollini KA, Maruyama AL \& Zimmerman CL, 2005. Planning for Restoration: A Decision Analysis Approach to Prioritization. Restoration Ecology, 13:460-470. http:// dx.doi.org/10.1111/j.1526-100X.2005.00057.x

Conselho Nacional do Meio Ambiente - CONAMA, 2010. Resolução Conama no 425. Available from: <http://www. mma.gov.br/port/conama/legiabre.cfm?codlegi $=630>$. Access in: 01 Mar 2013.

Echeverria C, Gatica P \& Fuentes R. 2013. Habitat edge contrast as an indicator to prioritize sites for ecological restoration at the landscape scale. Natureza \& Consevação, 11:170-175.

Garcia L et al. 2013. Restoration challenges and opportunities for increasing landscape connectivity under the new Brazilian Forest Act. Natureza \& Consevação, 11:181-185.

Garcia D \& Martinez D, 2012. Species richness matters for the quality of ecosystem services: a test using seed dispersal by frugivorous birds. Proceedings of the Royal Society B: Biological Sciences, 279:3106-3113. http://dx.doi.org/10.1098/ rspb.2012.0175

Gilbert-Norton L et al., 2009. A Meta-Analytic Review of Corridor Effectiveness. Conservation Biology, 24:660-668. http://dx.doi.org/10.1111/j.1523-1739.2010.01450.x

Hobbs RJ \& Norton DA, 1996. Towards a conceptual framework for restoration ecology. Restoration Ecology, 4:93-110. http:// dx.doi.org/10.1111/j.1526-100X.1996.tb00112.x

Holl KD \& Aide TM, 2011. When and where to actively restore ecosystems? Forest Ecology and Management, 261:1558-1563. http://dx.doi.org/10.1016/j.foreco.2010.07.004

Holvorcem CGDA et al., 2011. Anchor Areas to Improve Conservation and Increase Connectivity within the Brazilian Mesopotamia of Biodiversity. Natureza \& Conservação, 9:225-231. http://dx.doi.org/10.4322/natcon.2011.030

Joint Research Center - European Commission, 2011. Graphical User Interface for the Description of image Objects and their Shapes - GUIDOS software. Available from: $<\mathrm{http}$ ://forest. jrc.ec.europa.eu/download/software/guidos $>$. Access in: 01 Mar 2013.
Lamb D, Erskine PD \& Parrotta JA, 2005. Restoration of Degraded Tropical Forest Landscapes. Science, 310:16281632. http://dx.doi.org/10.1126/science.1111773

Lovett GM et al., 2005. Ecosystem function in heterogeneous landscapes. New York: Springer-Verlag, Inc. p. 489. http:// dx.doi.org/10.1007/b104357

Majka D, Jenness J \& Beier P, 2007. CorridorDesigner: ArcGIS tools for designing and evaluating corridors. Available from: $<$ http://corridordesign.org $>$.

Martensen AC. 2008. Importância relativa da perda e da fragmentação do habitat (tamanho do fragmento $e$ conectividade) na conservação de espécies em paisagens alteradas. [Dissertação]. São Paulo: Instituto de Biociências, Universidade de São Paulo.

Martensen A, Pimentel R \& Metzger JP, 2008. Relative effects of fragment size and connectivity on bird community in the Atlantic Rain Forest: Implications for conservation. Biological Conservation, 141:2184-2192. http://dx.doi org/10.1016/j.biocon.2008.06.008

Martensen AC et al., 2012. Associations of forest cover, fragment area, and connectivity with neotropical understory bird species richness and abundance. Conservation Biology, 26:1100-1111. http://dx.doi. org/10.1111/j.1523-1739.2012.01940.x

Mansourian S, Vallauri D \& Dudley N (eds. in cooperation with WWF International), 2005. Forest restoration in landscapes: beyond planting trees. New York: Springer. 437 p.

McGarigal K, Cushman SA \& Ene E, 2012. FRAGSTATS v4: Spatial Pattern Analysis Program for Categorical and Continuous Maps. Computer software program produced by the authors at the University of Massachusetts, Amherst. Available from: $<$ http://www.umass.edu/landeco/research/ fragstats/fragstats.html>.

Metzger JP, 2003. Como restaurar a conectividade de paisagens fragmentadas? In: Kageyama PY et al. Restauração ecológica de ecossistemas naturais. Botucatu: FEPAF. v. 3, p. 51-76.

Metzger JP, 2010. O Código Florestal tem base científica? Natureza \& Conservação, 8:92-99. http://dx.doi.org/10.4322/ natcon.00801017

Metzger JP et al., 2008. Uso de índices de paisagem para a definição de ações de conservação e restauração da biodiversidade do Estado de São Paulo. In: Rodrigues RR et al. (eds.). Diretrizes para Conservação e Restauração da Biodiversidade no Estado de São Paulo. São Paulo: Secretaria do Meio Ambiente e Fapesp. p. 120-127.

Rempel RS, Kaukinen D \& Carr AP, 2012. Patch Analyst and Patch Grid. Ontario Ministry of Natural Resources. Thunder Bay: Centre for Northern Forest Ecosystem Research.

Pressey RL et al., 2009. The C-plan conservation planning system: origins, applications, and possible futures. In: Spatial conservation prioritization: quantitative methods and computational tools. Oxford: Oxford University Press. p. 211-234.

Ribeiro MC et al., 2011. The Brazilian Atlantic Forest: a shrinking biodiversity hotspot. In: Zachos FE \& Habel JC (org.). Biodiversity Hotspots: Distribution and Protection of 
Conservation Priority Areas. London New York: SpringerVerlag Berlin Heidelberg. v. 1, p. 405-434.

Rodrigues RR et al., 2009. On the restoration of high diversity forests: 30 years of experience in the Brazilian Atlantic Forest. Biological Conservation, 142:1242-1251. http:// dx.doi.org/10.1016/j.biocon.2008.12.008

Rodrigues RR et al., 2011. Large-scale ecological restoration of high-diversity tropical forests in SE Brazil. Forest Ecology and Management, 261:1605-1613. http://dx.doi.org/10.1016/j. foreco.2010.07.005

Saunders DA, Hobbs RJ \& Margules CR, 1991. Biological consequences of ecosystem fragmentation: a review. Conservation Biology, 5:18-32. http://dx.doi. org/10.1111/j.1523-1739.1991.tb00384.x

Tambosi LR \& Metzger JP, 2013. A framework for setting local restoration priorities based on landscape context. Natureza \& Consevação, 11:152-157.
Tambosi LR et al., In press. A Framework to Optimize Biodiversity Restoration Efforts Based on Habitat Amount and Landscape Connectivity. Restoration Ecology. http:// dx.doi.org/10.1111/rec.12049

Thomson JR et al., 2009. Where and when to revegetate: a quantitative method for scheduling landscape reconstruction. Ecological Applications, 19:817-828. http://dx.doi. org/10.1890/08-0915.1

Twedt DJ, Uihlein III WB \& Elliott AB, 2006. A spatially explicit decision support model for restoration of forest bird habitat. Conservation Biology, 20:100-110. http:// dx.doi.org/10.1111/j.1523-1739.2005.00303.x

Wiens JA, 1997. Metapopulation dynamics and landscape ecology. In: Hanski I \& Gilpin ME (eds.). Metapopulation biology: ecology, genetics, and evolution. San Diego: Academic Press. p. 43-62. http://dx.doi.org/10.1016/ B978-012323445-2/50005-5

Received: April 2013

First Decision: July 2013

Accepted: November 2013 